\title{
A STUDY ON INTRAOPERATIVE AWARENESS AND RECALL DURING GENERAL ANAESTHESIA- A PROSPECTIVE OBSERVATIONAL STUDY
}

\author{
Arshid Ahmad' ${ }^{1}$ Mohamad Ommid², Shaiqa Manzoor ${ }^{3}$, Abraq Asma $^{4}$, Saba Ahad 5 , Hina Bahir 6 , Arshi Taj ${ }^{7}$, Humera Manzoor ${ }^{8}$ \\ ${ }_{1}^{1}$ Postgraduate Scholar, Department of Anaesthesiology and Critical Care, Government Medical College, Srinagar, J\&K, India. \\ ${ }^{2}$ Assistant Professor, Department of Anaesthesiology and Critical Care, Government Medical College, Srinagar, J\&K, India. \\ ${ }^{3}$ Postgraduate Scholar, Department of Anaesthesiology and Critical Care, Government Medical College, Srinagar, J\&K, India. \\ ${ }^{4}$ Lecturer, Department of Anaesthesiology and Critical Care, Government Medical College, Srinagar, J\&K, India. \\ ${ }^{5}$ Lecturer, Department of Anaesthesiology and Critical Care, Government Medical College, Srinagar, J\&K, India. \\ ${ }^{6}$ Associate Professor, Department of Anaesthesiology and Critical Care, Government Medical College, Srinagar, J\&K, India. \\ ${ }^{7}$ Assistant Professor, Department of Anaesthesiology and Critical Care, Government Medical College, Srinagar, J\&K, India. \\ ${ }^{8}$ Lecturer, Department of Anaesthesiology and Critical Care, Government Medical College, Srinagar, J\&K, India.
}

\section{ABSTRACT}

\section{BACKGROUND}

Intraoperative awareness occurs when a patient becomes conscious during a surgical procedure performed under general anaesthesia and subsequently has recall of these events. The experience can be quite disturbing and traumatic, and some patients may even need counselling after their surgery to help lessen feelings of confusion, stress, or trauma associated with the experience. For this reason, anaesthesia professionals are seriously committed to minimising the risk of intraoperative awareness under general anaesthesia.

Objectives- The purpose of this study was to evaluate the incidence of awareness with recall after surgery, which is an infrequent occurrence but of significant concern with significant adverse psychological sequelae and medicolegal implications.

\section{MATERIALS AND METHODS}

300 patients were enrolled for three different subsets of surgical patients undergoing general anaesthesia. An acknowledged and well-established method of detecting awareness involved the use of a structured Brice et al interview, 1970 and correlation with intraoperative Entropy monitoring.

\section{RESULTS}

Our study found that among these 300 patients, 2 patients reported remembering something between going to sleep and waking up from anaesthesia, thus 2 cases of awareness were identified. 7 patients reported dreaming and 4 cases of possible awareness were identified.

\section{CONCLUSION}

Awareness occurs despite the usual clinical monitoring of anaesthetic depth like BP, HR and even with the use of entropy. There is currently no evidence that awareness and recall could be prevented by monitoring consciousness with sophisticated methods such as BIS or entropy. If a patient has suffered from awareness and recalls this postoperatively, psychiatric consultation and followup is recommended.

\section{KEYWORDS}

Awareness, General Anaesthesia Depth, Entropy, Dreams.

HOW TO CITE THIS ARTICLE: Ahmad A, Ommid M, Manzoor S, et al. A study on intraoperative awareness and recall during general anaesthesia- A prospective observational study. J. Evolution Med. Dent. Sci. 2017;6(68):4872-4878, D0I: 10.14260/Jemds/2017/1056

\section{BACKGROUND}

Awareness with recall after surgery under general anaesthesia is an infrequent but well-described adverse outcome,(1) despite its relatively infrequent occurrence awareness is of significant concern to the patients(2) and is often associated with significant adverse psychological sequelae including Post-Traumatic Stress Disorder. $(3,4,5)$ The

Financial or Other, Competing Interest: None.

Submission 19-07-2017, Peer Review 13-08-2017,

Acceptance 19-08-2017, Published 24-08-2017.

Corresponding Author:

Dr. Mohamad Ommid,

Assistant Professor,

Department of Anaesthesiology and Critical Care,

Government Medical College,

Srinagar, J\&K, India.

E-mail:ommid76@yahoo.com

DOI: $10.14260 /$ jemds $/ 2017 / 1056$ occurrence of awareness is often the consequence of light anaesthetic technique or smaller anaesthetic doses. ${ }^{(6,7)}$ The first case report of traumatic awareness and recall during general anaesthesia was described in 1950 by Winterbottom. Studies on the incidence of awareness began in 1960s.

Awareness during anaesthesia falls in the domain of anaesthetist, so anaesthetist is held responsible in such cases. Very large compensations have been awarded for awareness during anaesthesia in Great Britain (Payne 1994). An analysis of ASA closed claim project showed that $1.9 \%$ of claims were for awareness and blamed substandard care.(8)

\section{Classification of Awareness}

Awareness during general anaesthesia includes consciousness and memory about intraoperative events. Memory about intraoperative events can be divided into. 


\section{Explicit}

Which is controlled consciousness and patient can recall spontaneously or in a structured post-operative interview.

\section{Implicit}

Which is automatic and unconscious component not recalled.

Implicit memory refers to changes in behaviour or performance but without any conscious recollection of previous experiences.

The term awareness is usually used to describe explicit memory, in fact explicit recall of intraoperative events during general anaesthesia.(1,9)

\section{Incidence and Prevalence}

The prevalence of awareness among non-cardiac and nonobstetric cases is $0.1 \%$ to $0.2 \%(1,3)$ In a study from Australia, Myles et al reported a frequency of awareness of $0.1 \%$.(2) The $^{(2)}$ prevalence in cardiac cases ranges from 1.1 to $1.5 \%$, in obstetric cases $0.4 \%$ and in major trauma cases $11-43 \% .(26,9,10,11)$

Sadin et al(3) performed one of the largest study on this topic which included 11785 patients, they identified 18 cases of awareness and reported an overall incidence of $0.16 \%$. Prevalence of awareness was $0.18 \%$ in cases in which NMB agents were used and $0.1 \%$ in absence of NMB agents.

A multicentre US study on incidence of awareness during anaesthesia interviewed 19,575 patients postoperatively and found 25 cases of awareness ( $0.13 \%$ incidence), a rate of $1-2$ cases per thousand patients.

Since the 1960s when first studies were published the incidence of this complication has declined from $1.2 \%$ to $0.1 \%$. Several studies have shown that females are at increased risk of awareness (Renta et al 1997, Ghoniem et al 2009). Large trials have demonstrated that around 1-2 per thousand patients experience some form of awareness.

Awareness is more frequent with major traumas that are followed by hypovolaemia and hypotension, cardiac surgeries, Caesarean-sections, interventions that are carried out at night. $(9,12,13)$ Now a days intubation is often achieved with long acting relaxants which are effective for longer time than the induction agents. What may therefore happen when short acting induction agents are combined with long acting muscle relaxants is that the induction agents ceases to be effective before the maintenance agents have caused sufficient depth of anaesthesia. The result is that the patient is awake but this is difficult to establish because of complete curarisation.(14,15)

Not giving premedication could be another important factor because premedication helps reduce anxiety before operation and may also act as sedative, even intensify the effect of anaesthetics, nowadays; however, premedication is no longer given routinely particularly in cases where a rapid recovery is desired. As a consequence of increased anxiety and lower level of sedation the chances of awareness are increased. $(16,17,18)$

\section{Causes Of Anaesthesia Awareness:(12)}

- Inadequate anaesthetic dose-emergency, trauma, hypovolemic patients, emergency cesarean-section, cardiac surgery.

- Resistance to anaesthetic-hyperthyroidism, obesity, anxiety, younger age, long time use of certain drugs (Alcohol, opiates or amphetamines).
- Routine administration of muscle relaxants.

- Mechanical malfunction or misuse of anaesthetic machine.

- Anaesthetic technique?

\section{Consequences and Sequelae of Awareness}

The spectrum of awareness ranges from simple perception of sensory stimuli to sensation of paralysis, feeling of helplessness, anxiety, panic and impending death. Most cases of awareness describe their experience in terms of anxiety both during the period of perception of incoming stimuli and in the postoperative period. Moreover, they all emphasise on feelings of powerlessness. Both these factors have an emotional impact and long psychological consequences. The main reason for this distress is not because they were awake but because they were not able to let anyone know that they were awake and not able to move, this leads to great anxiety. The intense anxiety has consequences like sleep disturbances, not daring to go to sleep, nightmares and waking up with anxiety are mentioned most frequently. These problems may last from few weeks to few months or longer. Another characteristic feature is an increased fear of anaesthesia. In serious cases, this may manifest as Posttraumatic stress disorder, which appears in 33\%-56\% of patients who experienced awareness. $(19,20,21)$

In 1937, Guedel published his classic text describing the stages and planes of ether anaesthesia relating them to clinical signs.(22,23) Traditionally, the judgement of inadequate general anaesthesia has been based on clinical signs such as heart rate, blood pressure, sweating, pupillary dilatation and lacrimation. However, signs of increased autonomic activity have not been associated with all cases of awareness and they may also be absent due to use of opioids, cholinergic and beta adrenergic antagonists, vasodilators and antihypertensive drugs and are therefore inadequate to measure the depth of general anaesthesia. $(5,7,12,13,24)$

EEG is classically classified as alpha, beta, delta and omega waves depending on their frequency and other parameters. BIS is an example of passively processed EEG. The BIS monitor is the most used and studied hypnotic monitor till now. The BIS value is described using arbitrary units that ranges from 100-awake to zero-isoelectric EEG and the recommended value for surgical anaesthesia is 40-60. Use of BIS has been shown to reduce the incidence of awareness during general anaesthesia in both high risk (Myles 2004) and mixed patient pool. In a prospective cohort trial of 4945 patients, BIS monitoring reduced the incidence of awareness from $0.18 \%$ to $0.04 \% .(22,24,25,26)$ Entropy was defined already in 1948 in the information theory by Shannan and applied to a power spectrum signal in 1984 by Jhonson and Shove. Mentropy is an online depth of anaesthesia monitor based on calculation of spectral entropy. Entropy parameters range from 0 to 100 (full awake).(27,28,29) Other monitoring methods include: Photoplethysmography/pulse oximetry, (30,31) AAI, EMG, Surgical stress index and surgical pleth index. The aim of this study was to observe the incidence of awareness in three subset populations of surgical patients we receive at our hospital using a standardised questionnaire and intraoperative entropy monitor. 


\section{Aims of the Study}

To find the incidence of awareness and recall in patients who undergo different types of surgeries under general anaesthesia.

\section{MATERIALS AND METHODS}

An acknowledged and well-established method of detecting awareness involves the use of a structured Brice et al interview 1970 which asks the following questions:(18)

1. What was the last thing you remember happening before you went to sleep?

2. What was the first thing you remember happening on waking up?

3. Did you dream or have any other experience in between?

4. What is the worst thing you remember about your operation/anaesthesia?

The Present study was conducted at the Associated Hospitals of Government Medical College, Srinagar-

1. Govt. L.D. Hospital: 100 patients from January 1, 2013 to June 30, 2013.

2. Govt. SMHS Hospital: 200 patients from August 1, 2013 to November 15, 2013, which includes 100 patients who underwent different routine general surgeries and 100 patients from Emergency.

After obtaining approval from hospital ethics committee, a written informed consent was taken from the patients for participation in this study.

\section{Patients who were excluded}

1. Patients with abnormal mental status.

2. Patients not expected to survive.

3. Patients Transferred directly to ICU.

4. Patients who belong to Extremes of age $(<15$ and $>60)$.

Pre-anaesthetic evaluation was done and noted down. In the operating room IV line established, multichannel monitor attached and standard monitoring including baseline pulse, NIBP, $\mathrm{SPO}_{2}$ and ECG connected. Entropy and NM monitoring equipment was attached.

The choice of inducing agent, neuromuscular blocker and maintenance for general anaesthesia was based on the patient and nature of surgical procedure.

\section{Design of the Study and Setting}

A prospective observational study for the incidence of awareness with recall during general anaesthesia was conducted. Patients for elective or urgent surgery requiring general anaesthesia were selected.

\section{Patient Interview, Detection and Evaluation}

Our definition of awareness is when patient spontaneously or at interview stated or remembered that he or she was awake during operation.

\section{Awareness Classification}

- AWR-YES: when patient in response to structured questions is sure of having been awake at any time during the operation.

- $\quad$ AWR-NO: when patient is sure of having been asleep during anaesthesia and operation.
- AWR-POSSIBLE: when patient believes to have been awake and aware during anaesthesia/operation but not sure.

- $\quad$ Dreams: YES or NO.

The detection of awareness depends on the interview technique, timing of interview and structure of interview. $(32,33)$

Protocol for Patient Detection and followup of the Intraoperative Awareness with Recall-

- $\quad$ Structured interview in PACU on day of surgery.

- Confirmative structured interview by study coordinator 3 days after surgery.

- $\quad$ Structured telephonic interview 30 days after surgery to explain possible cause and propose psychological treatment or advice.

- Analysis of possible cause of awareness from data of anaesthesia record. $(34,35)$

Total number of Patients selected and Evaluated for the Study $=300$, which includes:

1. General surgical cases: 200 at SMHS.

2. Gynaecological and obstetrical cases: 100 at LDH.

In SMHS, out of 200 patients, (n/\%)

- $\quad$ Awareness cases $=1(0.5 \%)$.

- $\quad$ Possible awareness $=3(1.5 \%)$.

- $\quad$ Dreams $=5(2.5 \%)$.

\section{In LDH out of 100 patients, (n/\%)}

- $\quad$ Awareness cases = $1(1 \%)$.

- $\quad$ Possible awareness $=1(1 \%)$.

- $\quad$ Dreams $=2(2 \%)$.

\section{Statistical Methodology}

The recorded data was compiled and entered in a spreadsheet (Microsoft Excel) and then exported to data editor of SPSS Version 20.0 (SPSS Inc./Chicago, Illinois, USA). Continuous variables were summarised in the form of means and standard deviations and categorical variables were expressed as frequencies and percentages. Graphically the data was presented as bar diagrams. Chi - square test was applied for comparing categorical variables. A P-value of $<0.05$ was considered statistically significant. All $\mathrm{P}$ values were two tailed.

\section{RESULTS}

\begin{tabular}{|c|c|c|c|c|c|}
\hline \multirow{2}{*}{ Hospital } & \multicolumn{3}{|c|}{ Awareness Study Results } & \multirow{2}{*}{ Total } \\
\cline { 2 - 6 } & Awareness & No & Possible & \\
\hline \multirow{2}{*}{ LDH } & $(\mathrm{n})$ & 1 & 98 & 1 & 100 \\
\cline { 2 - 6 } & $(\%)$ & $1.0 \%$ & $98.0 \%$ & $1.0 \%$ & $100.0 \%$ \\
\hline \multirow{2}{*}{ SMHS } & $(\mathrm{n})$ & 1 & 196 & 3 & 200 \\
\cline { 2 - 6 } & $(\%)$ & $0.5 \%$ & $98.0 \%$ & $1.5 \%$ & $100.0 \%$ \\
\hline \multirow{2}{*}{ Total } & $(\mathrm{n})$ & $\mathbf{2}$ & $\mathbf{2 9 4}$ & $\mathbf{4}$ & $\mathbf{3 0 0}$ \\
\cline { 2 - 6 } & $\mathbf{( \% )}$ & $\mathbf{0 . 7 \%}$ & $\mathbf{9 8 . 0} \%$ & $\mathbf{1 . 3 \%}$ & $\mathbf{1 0 0 . 0 \%}$ \\
\hline \multicolumn{3}{|c|}{ Table 1. A wareness and Dreams Study Results: } \\
\hline
\end{tabular}

${ }^{*}$ Pearson Chi-square $=0.375$, P-value $=0.829$ (nonsignificant) 


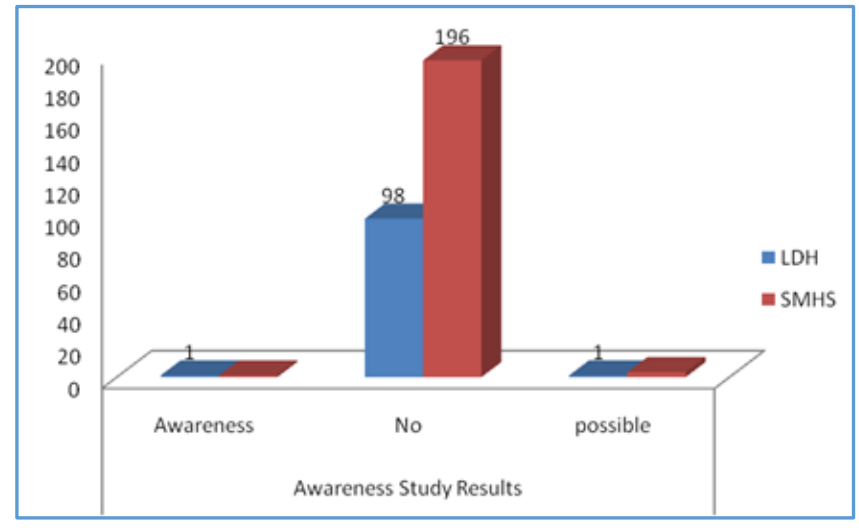

Figure 1. Awareness Study Results (Bar Chart): Different Hospitals

\begin{tabular}{|c|c|c|c|c|}
\hline \multirow{2}{*}{\multicolumn{2}{|c|}{ Hospital }} & \multicolumn{2}{|c|}{ Dreams } & \multirow{3}{*}{$\begin{array}{c}\text { Total } \\
100\end{array}$} \\
\hline & & \multirow{2}{*}{$\begin{array}{c}\text { No } \\
98\end{array}$} & \multirow{2}{*}{$\begin{array}{c}\text { Yes } \\
2\end{array}$} & \\
\hline IDH & (n) & & & \\
\hline LDI1 & $(\%)$ & $98.0 \%$ & $2.0 \%$ & $100.0 \%$ \\
\hline \multirow{2}{*}{ SMHS } & (n) & 195 & 5 & 200 \\
\hline & $(\%)$ & $97.5 \%$ & $2.5 \%$ & $100.0 \%$ \\
\hline \multirow{2}{*}{ Total } & (n) & 293 & 7 & 300 \\
\hline & $(\%)$ & 97.7\% & $2.3 \%$ & $100.0 \%$ \\
\hline \multicolumn{5}{|c|}{ Table 2. Incidence of Dreams } \\
\hline
\end{tabular}

*Pearson Chi-Square $=0.073$, p-value $=0.571$ (nonsignificant)

Awareness and Dreams Study Results as per Nature of Surgery

Elective

- $\quad$ Total no. of cases $=145$.

- $\quad$ Awareness $=0$ (0.\%).

- $\quad$ Possible awareness $=1(0.7 \%)$.

\section{Emergency}

- Total no. of cases= 155 .

- $\quad$ Awareness $=2(1.3 \%)$.

- $\quad$ Possible awareness $=3(1.9 \%)$.

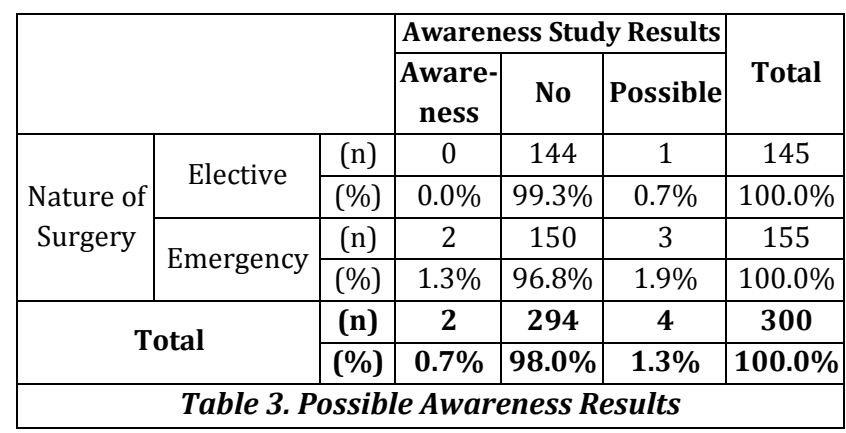

Pearson Chi-Square $=2.792 \mathrm{p}$ value $=0.248$ (non-significant $)$.

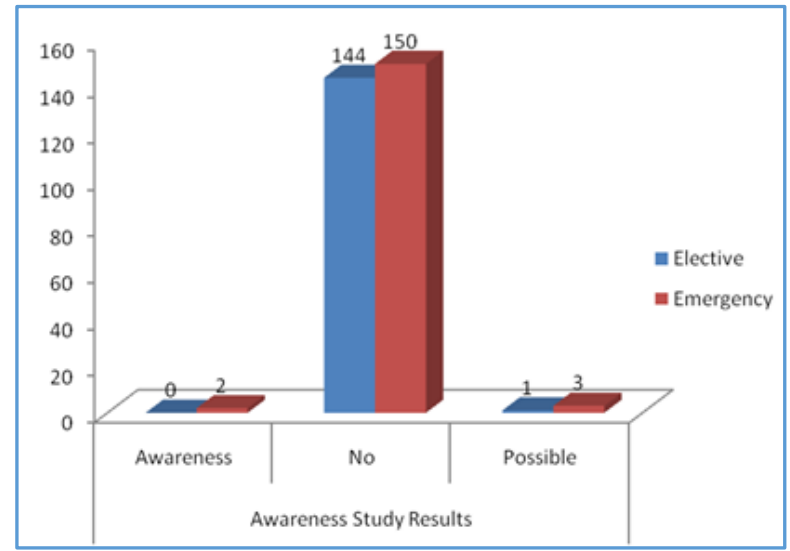

Figure 2. Awareness Study Results: Elective versus Emergency

\begin{tabular}{|c|c|c|c|c|c|}
\hline \multirow{2}{*}{\multicolumn{3}{|c|}{ Crosstab }} & \multicolumn{2}{|c|}{ Dreams } & \multirow{3}{*}{$\begin{array}{c}\text { Total } \\
145\end{array}$} \\
\hline & & & \multirow{2}{*}{$\begin{array}{c}\text { No } \\
140 \\
\end{array}$} & \multirow{2}{*}{$\begin{array}{c}\text { Yes } \\
5 \\
\end{array}$} & \\
\hline \multirow{4}{*}{$\begin{array}{l}\text { Nature of } \\
\text { Surgery }\end{array}$} & \multirow{2}{*}{ Elective } & (n) & & & \\
\hline & & (\%) & $96.6 \%$ & $3.4 \%$ & $100.0 \%$ \\
\hline & \multirow{2}{*}{ Emergency } & (n) & 153 & 2 & 155 \\
\hline & & $(\%)$ & $98.7 \%$ & $1.3 \%$ & $100.0 \%$ \\
\hline \multirow{2}{*}{\multicolumn{2}{|c|}{ Total }} & (n) & 293 & 7 & 300 \\
\hline & & (\%) & $97.7 \%$ & $2.3 \%$ & $100.0 \%$ \\
\hline
\end{tabular}

Table 4. Incidence of Dream: Elective versus Emergency

*Pearson Chi-Square=1.531 p value=.216 (nonsignificant)

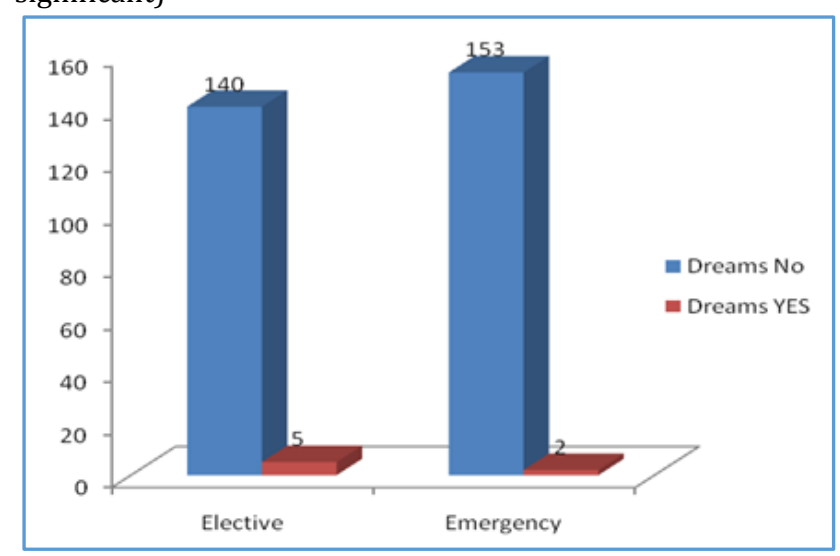

Figure 3. Bar Chart Representation Incidence of Dreams in Elective versus Emergency Patients

\begin{tabular}{|c|c|c|c|c|c|c|}
\hline \multicolumn{7}{|c|}{ Crosstab } \\
\hline & & & \multicolumn{3}{|c|}{ Awareness Study Results } & \multirow{2}{*}{ Total } \\
\hline & & & Awareness & No & Possible & \\
\hline \multirow{4}{*}{ Gender } & \multirow{2}{*}{$F$} & (n) & 2 & 194 & 3 & 199 \\
\hline & & $(\%)$ & $1.0 \%$ & $97.5 \%$ & $1.5 \%$ & $100.0 \%$ \\
\hline & \multirow{2}{*}{$\mathrm{M}$} & (n) & 0 & 100 & 1 & 101 \\
\hline & & $(\%)$ & $0.0 \%$ & $99.0 \%$ & $1.0 \%$ & $100.0 \%$ \\
\hline \multirow{2}{*}{\multicolumn{2}{|c|}{ Total }} & (n) & 2 & 294 & 4 & 300 \\
\hline & & $(\%)$ & $0.7 \%$ & 98.0\% & $1.3 \%$ & $100.0 \%$ \\
\hline \multicolumn{7}{|c|}{$\begin{array}{l}\text { Table 5. Awareness and Dreams } \\
\text { Study Results as per Gender }\end{array}$} \\
\hline
\end{tabular}

Pearson Chi-Square $=1.165, \mathrm{P}$ value $=0.558$ (non-significant) 


\begin{tabular}{|c|c|c|c|c|c|}
\hline & \multicolumn{2}{|c|}{ Dreams } & \multirow{2}{*}{ Total } \\
\hline & & & No & Yes & \\
\hline \multirow{4}{*}{ Gender } & \multirow{2}{*}{ F } & \multirow{2}{*}{$\begin{array}{l}\text { (n) } \\
(\%)\end{array}$} & 195 & 4 & 199 \\
\hline & & & $98.0 \%$ & $2.0 \%$ & $100.0 \%$ \\
\hline & \multirow{2}{*}{ M } & (n) & 98 & 3 & 101 \\
\hline & & (\%) & $97.0 \%$ & $3.0 \%$ & $100.0 \%$ \\
\hline \multirow{2}{*}{\multicolumn{2}{|c|}{ Total }} & (n) & 293 & 7 & 300 \\
\hline & & (\%) & $97.7 \%$ & $2.3 \%$ & $100.0 \%$ \\
\hline
\end{tabular}

Table 6. Gender wise Incidence

${ }^{*}$ Pearson Chi-Square $=0.271, \mathrm{P}$ value $=0.603$ (non-significant $)$

\begin{tabular}{|c|c|c|c|c|c|c|}
\hline \multicolumn{7}{|c|}{ Crosstab } \\
\hline & & & \multicolumn{3}{|c|}{ Awareness Study Results } & \multirow{2}{*}{ Total } \\
\hline & & & Awareness & No & Possible & \\
\hline \multirow{4}{*}{ ASA } & \multirow{2}{*}{ I } & (n) & 1 & 233 & 3 & 237 \\
\hline & & (\%) & $0.4 \%$ & $98.3 \%$ & $1.3 \%$ & $100.0 \%$ \\
\hline & \multirow{2}{*}{ II } & (n) & 1 & 61 & 1 & 63 \\
\hline & & (\%) & $1.6 \%$ & $96.8 \%$ & $1.6 \%$ & $100.0 \%$ \\
\hline \multirow{2}{*}{\multicolumn{2}{|c|}{ Total }} & (n) & 2 & 294 & 4 & 300 \\
\hline & & (\%) & $0.7 \%$ & $98.0 \%$ & $1.3 \%$ & $100.0 \%$ \\
\hline \multicolumn{7}{|c|}{$\begin{array}{l}\text { Table 7. Awareness and Dreams } \\
\text { Study Results as per ASA Class }\end{array}$} \\
\hline
\end{tabular}

${ }^{*}$ Pearson Chi-Square $=1.064, \mathrm{P}$ value $=0.588$ (non-significant $)$.

\begin{tabular}{|c|c|c|c|c|c|}
\hline & \multicolumn{2}{|c|}{ Dreams } & \multirow{2}{*}{ Total } \\
\hline & & & No & Yes & \\
\hline \multirow{4}{*}{ ASA } & \multirow{2}{*}{ I } & (n) & 231 & 6 & 237 \\
\hline & & (\%) & $97.5 \%$ & $2.5 \%$ & $100.0 \%$ \\
\hline & \multirow{2}{*}{ II } & (n) & 62 & 1 & 63 \\
\hline & & $(\%)$ & $98.4 \%$ & $1.6 \%$ & $100.0 \%$ \\
\hline \multirow{2}{*}{\multicolumn{2}{|c|}{ Total }} & (n) & 293 & 7 & 300 \\
\hline & & (\%) & $97.7 \%$ & $2.3 \%$ & $100.0 \%$ \\
\hline
\end{tabular}

${ }^{*}$ Pearson Chi-Square $=0.195, \mathrm{p}$ value $=0.659$ (non-significant)

These 300 patients were interviewed as per the protocol in PACU on the day of surgery.

Our study found that among these 300 patients, 2 patients reported remembering something between going to sleep and waking up from anaesthesia, thus 2 cases of awareness were identified. 7 patients reported dreaming and 4 cases of possible awareness were identified.

\section{DISCUSSION}

The detection of awareness depends on the interview technique, timing of the interview and structure of the interview. A postoperative visit by the anaesthesiologist without use of a structured interview is unlikely to elicit many cases of awareness. We used the same structured interview that has been used in prior investigations.(18) We interviewed the patients in the PACU.

In our study, 2 cases of awareness (0.7\%) and 4 cases of possible awareness (1.3\%) were identified. Our study is comparable to the previous study done by Sabel et al (The incidence of awareness during anaesthesia: A multicentre United States study) and study done by Seppo Ranta (Awareness with recall during general anaesthesia). Like these mentioned studies our study also shows that awareness and recall under general anaesthesia can occur despite using a proper anaesthetic technique and intraoperative monitoring including entropy.

The description of the awareness cases identified in this study closely resembles those reported previously. A significant proportion of awareness episodes occur either during endotracheal intubation or at surgical incision i.e. times when the level of patients stimulation is highest. (36)

Besides the abovementioned reported observations, many patients complained of auditory perceptions and being unable to move or breathe, anxiety, stress, panic, paralysis, pain and sensations of the endotracheal tube were also reported.

Dreaming during anaesthesia was described by 7 patients $(2.3 \%)$ and this is consistent with the common occurrence of perioperative dreaming reported in several European studies. $(18,36,20)$ Dreaming was more frequently reported in the recovery room than later after surgery. The significance of dreaming and its relationship to awareness during anaesthesia is unclear.

These awareness cases were followed retrospectively to study the intraoperative events and vitals, anaesthetic technique and preoperative status, including demographic data. We could not find any significant predictor of possible awareness in these cases of awareness. All the cases were monitored intraoperatively by using entropy from induction to emergence at fixed intervals of time and in these 2 cases of awareness entropy was found consistently above 60 but there was no association between increased entropy readings and the incidence of awareness as many patients had entropy above 60 but did not report awareness in our study.

Awareness is caused by the administration of general anaesthesia that is inadequate to maintain unconsciousness and to prevent recall during surgical stimulation. Common causes include large anaesthetic requirements, equipment misuse or failure and smaller doses of anaesthetic drugs.

Various studies found an increased risk of awareness with sicker patients undergoing major surgery, this finding may reflect the use of smaller anaesthetic doses and light anaesthetic techniques in sicker patients. ${ }^{(19)}$

In many cases, awareness during anaesthesia is a potentially avoidable adverse anaesthetic outcome. In light of followup studies suggesting that such victims of awareness may exhibit significant psychological after effects such as PTSD, attempts to further reduce its incidence are warranted.

Because awareness occurred despite the usual clinical monitoring of anaesthetic depth (BP, HR and end tidal anaesthetic monitoring), a monitor of cerebral function and depth of anaesthesia may be of theoretical benefit. $(3,5,7,8,19)$

The limitation of our study is that it did not assess the long term psychological sequelae of intraoperative awareness and recall among the victims.

\section{CONCLUSION}

Awareness is caused by the administration of general anaesthesia that is inadequate to maintain unconsciousness and to prevent recall during surgical stimulation.

Awareness occurs despite the usual clinical monitoring of anaesthetic depth like BP, HR and even with the use of entropy. 
There is currently no evidence that awareness and recall could be prevented by monitoring consciousness with sophisticated methods such as BIS or entropy. However, any clinical signs are much more unreliable in this respect and certainly it would be wise to use EEG based monitoring if a patient has history of awareness with recall under general anaesthesia.

If a patient has suffered from awareness and recalls this postoperatively, psychiatric consultation and followup is recommended.

\section{REFERENCES}

[1] Ghoneim MM. Awareness during anesthesia. Anesthesiology 2000;92(2):597-602.

[2] Myles PS, Williams DL, Hendrata M, et al. Patient satisfaction after anesthesia and surgery: results of a prospective survey of 10,811 patients. British Journal of Anesthesia 2000;84(1):6-10.

[3] Sandin RH, Enlund G, Samuelsson P, et al. Awareness during anesthesia: a prospective case study. Lancet 2000;355(9205):707-11.

[4] Osterman JE, Hopper J, Hearn WJ, et al. Awareness under anesthesia and the development of posttraumatic stress disorder. General Hospital Psychiatry 2001;23(4):198-204.

[5] Moerman N, Bonke B, Oosting J. Awareness and recall during general anesthesia. Facts and feelings. Anesthesiology 1993;79(3):454-64.

[6] Ranta SO, Laurila R. Saario J, et al. Awareness with recall during general anesthesia: incidence and risk factors. Anesthesia Analog 1998;86(5):1084-9.

[7] Domino KB, Posner KL, Caplan RA, et al. Awareness during anesthesia: a closed claims analysis. Anesthesiology 1999;90(4):1053-61.

[8] Domino KBA, Aitkenhead AR. Medicolegal aspects of awareness during anesthesia. In: Ghoniem MM. edr. Awareness during anesthesia. Oxford 2001:155-72.

[9] American Society of Anesthesiologists Task Force on Intraoperative Awareness. Practice advisory for intraoperative awareness and brain function monitoring: a report by American Society of Anesthesiologists Task Force on Intraoperative Awareness. Anesthesiology 2006;104(4):847-64.

[10] Errando CL, Sigl JC, Robles M, et al. Awareness with recall during general anesthesia: a prospective observational evaluation of 4001 patients. BJA 2008;101(2):178-85.

[11] Robins K, Lyons G. Intraoperative awareness during general anesthesia for cesarean delivery. Anesthesia Analog 2009;109(3):886-90.

[12] Bogetz MS, Katz JA. Recall of surgery for major trauma. Anesthesiology 1984;61(1):6-9.

[13] Radovanovic D, Radovanovic Z. Awareness during general anesthesia-implications of explicit intraoperative recall. European Review for Medical and Pharmacological Sciences 2011;15:1085-9.

[14] Ekman A, Lindholm ML, Lennmarken C, et al. Reduction in the incidence of awareness using BIS monitoring. Acta Anaesthesiol Scand 2004;48(1):20-6.

[15] Avidan MS, Zhang L, Burnside BA, et al. Anesthesia Awareness and the bi-spectral index. New England Journal of Medicine 2008;358(11):1097-108.
[16] Russell LF. Comparison of wakefulness with two anesthetic regimens. Total I.V. vs. balanced anesthesia. British Journal of Anesthesia 1986;58(9):965-8.

[17] Jessop J, Jones JG. Conscious awareness during general anesthesia-what are we attempting to monitor? British Journal of Anesthesia 1991;66(6):635-7.

[18] Brice DD, Hetherington RR, Utting JE. A simple study of awareness and dreaming during anesthesia. British Journal of Anesthesia 1970;42(6):535-42.

[19] Sebel PS, Bowdle TA, Ghoneim MM, et al. The incidence of awareness during anesthesia: a multicenter united states study. Anesthesia Analog 2004;99(3):833-9.

[20] Liu WH, Thorp TA, Graham SG, et al. Incidence of awareness with recall during general anesthesia. Anesthesia 1991;46(6):435-7.

[21] Bogod DG, Orton JK, Yau HM, et al. Detecting awareness during general anesthetic caesarean section. An evaluation of two methods. Anesthesia 1990;45(4):279-84.

[22] Lyons G, Macdonald R. Awareness during caesarean section. Anesthesia 1991;46(1):62-4.

[23] Pollard RJ, Coyle JP, Gilbert RL, et al. Intraoperative awareness in a regional medical system: a review of 3 years' data. Anesthesiology 2007;106(2):269-74.

[24] Mashour GA, Wang LYJ, Turner CR, et al. A retrospective study of intraoperative awareness with methodological implications. Anesthesia Analog 2009;108(2):521-6.

[25] Mashour GA, Orser BA, Avidan MS. Intraoperative awareness: from neurobiology to clinical practice. Anesthesiology 2011;114(5):1218-33.

[26] Orser BA. Depth-of-anesthesia monitor and the frequency of intraoperative awareness. New England Journal of Medicine 2008;358(11):1189-91.

[27] Kent CD, Mashour GA, Metzger NA, et al. Psychological impact of unexpected explicit recall of events occurring during surgery performed under sedation, regional anaesthesia and general anaesthesia: data from the Anesthesia Awareness Registry. Br J Anaesth 2013;110(3):381-7.

[28] Johansen JW. Update on bispectral index monitoring. Best Practice Res Clinical Anesthesia 2006;20(1):8199.

[29] Schmidt GN, Bischoff P, Standl T, et al. Comparative evaluation of the Datex-Ohmeda S/5 entropy module and the bispectral index monitor during propofolremifentanil anesthesia. Anesthesiology 2004;101: 1283-90.

[30] White PF, Tang J, Romero GF, et al. A comparison of state and response entropy versus bispectral index values during the perioperative period. Anesth Analg 2006;102(1):160-7.

[31] Wheeler P, Hoffman WE, Baughman VL, et al. Response entropy increases during painful stimulation. J Neurosurg Anesth 2005;17(2):86-90.

[32] Leslie K, Chan MT, Myles PS, et al. Posttraumatic stress disorder in aware patients from the B-aware trial. Anesth Analg 2010;110(3):823-8.

[33] Orser BA, Mazer CD, Baker AJ. Awareness during anesthesia. CMAJ 2007;178(2):185-8. 


\section{Jemds.com}

[34] Sneyd JR, Mathews DM. Memory and awareness during anaesthesia. British Journal of Anesthesia 2008;100(6):742-4.

[35] van Oud-Albas HJB, van Dijk M, Liu C, et al. Intraoperative awareness during paediatric anaesthesia. British Journal of Anesthesia 2009;102(1):104-10.

\section{Original Research Article}

[36] Lennmarken C, Bildfors K, Enlund G, et al. Victims of awareness. Acta Anaesthesiol Scand 2002;46(3):22931. 